\title{
Leadership for health care in the 2 I st Century: A personal perspective
}

\author{
This article was published in the following Dove Press journal: \\ Journal of Healthcare Leadership \\ II May 2010 \\ Number of times this article has been viewed
}

\author{
Harold C Slavkin \\ University of Southern California, \\ Los Angeles, CA, USA
}

Correspondence: Harold Slavkin Center for Craniofacial Molecular Biology, School of Dentistry, University of Southern California, 2250 Alcazar Street CSA- I03, Los Angeles, CA 90033, USA

$\mathrm{Tel}+\mathrm{I} 3234422216$

Fax + I 323442298 ।

Email slavkin@usc.edu

\begin{abstract}
From my perspective, there is no infallible step-by-step formula for becoming an effective or transformational leader. My assertion is that leadership can be taught and learned. Specifically, a person can observe and internalize select models of leadership from unique environments, and then use these "lessons learned" to foster a potential for leadership by learning about what's worked for others. By selecting "best practices" one can readily and selectively apply those lessons learned to one's own situation. Leadership opportunities abound in a broad array of environments including health professional education (eg, medicine, dentistry, pharmacy, nursing, physical therapy, occupational therapy, dental hygiene), academic health sciences centers, specific clinical disciplines in acadême, or in private as well as nonprofit clinical practices (eg, primary care, various specialties), domestic as well as international health policy, large and small hospitals and clinics, and a myriad of health care industries such as insurance, major pharmaceuticals, information technology, supplies, and the industries that embrace equipment manufacturers and distributors. I hope this "personal perspective" prompts and encourages the reader to think about leading and leadership, and qualities that often describe leaders such as integrity, being trustworthy, "learning organizations", and leading genius within the health care enterprise at this time in the 21 st Century.
\end{abstract}

Keywords: leadership, learning, best practice, health care, education

\section{Introduction}

A precise definition of leadership can often be elusive. Distinctions or clarifications are attempted with limited success between "leadership" as opposed to "management". Whether reflecting on your own experiences, browsing through bookstores, or searching on the Internet, you will readily find thousands of incarnations of "leadership". For my purposes in this "personal perspective", leadership signifies the act of "making a difference". Leadership generally entails sustaining, improving, or changing strategic directions within small or large, simple or complex, organizations. During the last 50 years in the United States, leadership - whether of the nation, state or city, a university, a foundation, or a company — has been characterized as building, creative, innovative, and generous. Today's era raises issues for leadership that focus on reducing social and health benefits, and downsizing workforces and related services. Leading requires making choices with finite resources based upon plausible alternatives, and it depends on motivating and bringing others along, on mobilizing and coordinating human and financial resources to achieve a common goal. Leadership at its best is when vision becomes strategic, the leader's voice becomes persuasive, and the results become tangible. submit your manuscript | www.dovepress.com

Dovepress

8082 
I have benefited enormously from many years within the leadership crucible at the University of Southern California (USC). University Professor Warren Bennis is a good friend and exemplar of the Marshall School of Business through his emphasis upon leadership and management education, and training relevant to all sectors of society. He is the founding chairman of the Leadership Institute at USC, and also serves as Chairman of the Center for Public Leadership at Harvard's Kennedy School of Government. ${ }^{1-3}$ Warren Bennis' definition of leadership is focused on the individual leader's qualities: "Leadership is a function of knowing yourself, having a vision that is well communicated, building trust among colleagues, and taking effective action to realize your own leadership potential". ${ }^{2,3}$

During the past few years, Professor Bennis has teamed with USC President Steven Sample to co-teach a selective course for university undergraduates as well as graduate and professional students, designed to explore the content and skills associated with leadership. President Sample's "The contrarian's guide to leadership" provides a leadership "manual" that highlights knowledge, eloquence, previous experiences or "case studies", and suggested skills for leading in the 21 st Century. ${ }^{4}$ Within this academic crucible, I have had numerous opportunities to develop my personal leadership as a tenured faculty member, academic department chair, director of a biomedical research center, dean of a health professional school, and as a member of President Steve Sample's leadership team (2000-2008). These experiences have also been enhanced through my leadership roles as President, American Association for Dental Research, and while working at the National Institute of Health on Director Harold Varmus' leadership team, serving as Director of the National Institute for Dental and Craniofacial Research (1995-2000). Additional leadership opportunities were afforded me through my associations with the Institute of Medicine (IOM), National Academy of Sciences (1996-present), The Santa Fe Group (1996-present), ${ }^{5}$ and as a Director, Board of Directors, of Patterson Company (PDCO) (2001-present).

\section{Leadership opportunities for the 2 I st Century}

Opportunities abound in the 21st Century for activities related to health care leadership in the United States. Perhaps as never before, leadership is urgently needed to envision the future, to reallocate resources, to monitor progress using information technology, and to engender both evidence-based as well as outcome-based health care for all Americans. Clearly these executive opportunities reside throughout the academic sector, public and private, through local, state and federal governments, from public health to private sector health care delivery, throughout all levels of biomedical research (eg, basic, translational, clinical, and outcomes research), health-related private industries (eg, manufacturing, distribution, insurance, etc) and, of course, throughout both public as well as private health care policy formulations.

According to a simple assertion made by Peter Drucker, "The only definition of a leader is someone who has followers". ${ }^{6}$ In a formal sense, "leaders" can be appointed for specific terms of tenure, voted into political positions, or informally assume a position of leadership within an informal setting. We know that to gain followers requires influence such as a formal appointment of a CEO by a Board of Directors of a corporation (public or private), a formal appointment by the President with Senate approval for an individual to lead a federal agency (eg, Secretary of Department of Treasury, Director of the National Institutes of Health), a formal appointment of a university president by a board of trustees of a private institution, or by election for public office (eg, federal, state, county, and/or city levels of government), or by election by a group to lead a local or community organization (eg, local PTA, sorority or fraternity). And we further know, that each of us are often presented with "leadership moments" when we least expect them.

In the formal sense, the evaluation or assessment of a leader's performance is often based upon qualitative (eg, integrity, character, trustworthiness, communication of mission and vision, the capability to influence) as well as quantitative measures (eg, financial gains, market share, acquisitions, leverage of assets, rankings as found for academic institutions in annual US News and World Report, federally-sponsored research gained by faculties through peer-review processes, peer-reviewed scientific or technical papers, success in gaining patent approval to protect intellectual property, percent students accepted into an academic institution, etc). For example, a major metric for the private sector might be stated simply as "the bottom line". Have the CEO and team increased net profits over some period of time, and what was the rate of increase? Has CEO leadership resulted in a greater market share? Under turbulent economic conditions, have the $\mathrm{CEO}$ and team sustained the enterprise through storms? What innovations were introduced by the CEO and which of these succeeded? Highly successful leaders, in all types of organizations, project the abilities to think and act strategically. They influence, motivate and inspire, thereby enabling others to realize their 
potential. They usually lead by example, and possess talents of a superb communicator, reflect selflessness, and are often perceived as making a significant difference to the organization or institution. ${ }^{1-4,6}$

One valuable assessment tool for evaluating a leader is found in the "360-degree feedback" also known as "multisource assessment". This strategy is designed to gain perspective from individuals selected from various positions around the leader such as trustees, provost, deans, faculty, students and staff, and other collegial presidents, for example, selected from around a private university president. These disparate points of view offer a leader or executive a remarkable set of assessments from which to engage in self-assessment as well as self-improvement: "How am I doing and how can I be better?"?

\section{Health professional education}

Technological, demographic, social, and economic forces will continue to have a significant impact on access and affordability to comprehensive, quality health care from prenatal through hospice care stages of life. Meeting the public's comprehensive health needs, and quality of life in the coming decade, will require transformational leadership and profound revisions in the entire health care enterprise. Many futurists assert that gaining synergy within and between health professional schools, departments and programs (eg, medicine, dentistry, pharmacy, nursing, physical and occupational therapy, speech therapy, and dental hygiene, etc), will be the key to best optimize the health care workforce to meet the changing health needs of society. The Institute of Medicine (IOM) of the National Academy of Sciences has engaged thousands of experts to delve into what is, and what should and could be, for health professional education, clinical practice, biomedical research including clinical and outcomes research, and continuing professional education for the early 21 st Century. ${ }^{8}$ In most of these reports the emphasis has been placed upon measurable outcomes, evidencebased health care, and robust informatics needed to manage the health care enterprise - patients, families, communities, health care providers, health care policies, costs and affordability, and quality and comprehensive health care.

Significantly, dozens of IOM reports focus on analyses of issues coupled with recommendations that will require leadership to achieve major revisions in the health care enterprise (eg, pre-doctoral and doctoral education models based upon inquiry-based learning, specialty training, evidence-based clinical practice coupled to bioinformatics, multidisciplinary professional continuing education, ongoing portfolio performance assessments and rewards, etc)..$^{9-11}$ One exemplar for the need of transformational leadership and recommendations can be found in the IOM report "Academic health centers: leading change in the 21 st Century". ${ }^{11}$

The meaning of "transformational" leadership through my prism is a form and style of leadership that literally provides "positive" changes in followers, enhancements or radical changes of infrastructure processes, and significantly increases performance and measurable outcomes. In this leadership model, the leader enhances motivation, morale, and performance. For example, a new leader recruited to a top-down, command and control, organization introduces a series of candid group discussions that audit the culture of the organization. Through strategic planning processes the leader slowly builds trust, flattens the hierarchy, rewards open criticism and suggestions, cultivates strategic versus tactical approaches, and routinely celebrates accomplishments both "big and small". The transformational leader stimulates organizational learning practices, nurtures, and grows a sense of "enlightened self-interest among all stakeholders". I have personally been involved in several such "transformational" experiences such as (1) changing the name and mission of a federal agency, (2) serving as the lead agency for the first-time ever Surgeon General's report "Oral health in America", (3) introducing institution-wide information technology to replace "paper-based processes", (4) introducing digital technology such as computer-aided design and computer-aided manufacturing (CAD-CAM) to design and fabricate prostheses, (5) introducing "learner-centered education" into a traditional passive learning organization, and (6) investing in life-long learning for all staff and faculty within a health professional school to change expectations and aspirations of the workforce. The cultural consequences resulting from such transformational leadership was to produce pride, trust, admiration, and loyalty and respect between faculty, staff, students, patients, and alumni. Candidly, such desired outcomes can be achieved within $70 \%$ of the entire organization but never in $100 \%$. The leader's expectations are very important.

A few examples are highlighted to illustrate opportunities for major revisions in health professional education in response to societal needs and IOM recommendations. One example is the introduction of problem-based learning into health professional education, specially medical and dental education. ${ }^{12-16}$ Another is the innovation to introduce an expanded "oral health curriculum" into the medical education for physicians at the University of Washington. ${ }^{17}$ Yet another is the innovation a few years ago to realign the College of 
Nursing with the College of Dentistry at New York University. A fourth example is the new realignment of the Program in Biokinesiology and Physical Therapy, and the Program of Occupational Science and Occupational Therapy, with the School of Dentistry at the University of Southern California. Each of these examples provided enhanced opportunities for transdisciplinary professional education, research, and patient and community health care.

Achieving health and well being for all Americans will require leadership at many levels of the enterprise, the strategic management systems necessary to create environments conducive for innovations, and coordinated and cohesive system-wide views across disparate disciplines and values. Leadership is imperative to build and sustain information systems, rewards and mechanisms for accountability that can measure and reward accomplishments. Leadership training, development, and support are critical for the present and future of health care diverse organizations and institutions. ${ }^{1-6,18,19}$ The scope of the suggested content for such leadership development courses within a "learning organization" includes defining leadership models in their social context, analysis of strategic versus tactical approaches to problem solving, learning to listen and analyze before making decisions, oral and written communication styles, resource management, creating coalitions and collaborations, leveraging resources, conflict resolution, fiscal and specific budget management, and creating environments of trust (after Peter Senge). ${ }^{18,19}$ It also means leading for measurable results, managing change, and personal and team life-long learning and development. ${ }^{18,19}$

\section{Biomedical research}

The biological and digital revolutions have yielded remarkable advances that have and continue to profoundly influence a paradigm shift in health care. Genomics, postgenomics and the dividends from the transcriptome, proteome, metabolome, and the microbiome, with accompanying bioinformatics, information technology, and imaging, are shaping health care in the 21 st Century. ${ }^{9-11,20}$ In tandem, remarkable health disparities based upon socioeconomic determinants have also been illuminated. These "drivers" add additional complexity for leadership in biomedical science and technology. Success in these endeavors is often dependent upon cooperation and collaboration between "different ways of knowing" or so-called multidisciplinary or transdisciplinary team approaches. Leadership in these fields of inquiry requires organizing highly creative people into effective collaborative groups or teams, motivated by common goals and incentives. Three examples, requiring very different but highly effective transformational leadership skill sets, include J Robert Oppenheimer and The Manhattan Project of World War II, Francis Collins and The Human Genome Project (1988-2004), ${ }^{20}$ and the International SARS Consortium ("team-driven"), and The SARS Project created to rapidly define and understand the nature of SARS virus in February and March 2003. ${ }^{21}$ Not only are the results noteworthy from these three different examples, the processes used to achieve these remarkable outcomes must to be studied. ${ }^{20,21}$

Biomedical research leadership positions abound throughout public and private academic organizations, state and federal research organizations, nonprofit foundations, as well as the medical device, biotechnology, and pharmaceutical industries. Importantly, old stereotypes have been challenged and new paradigms have emerged.

The distinct organization of the health and biomedical research professions into specialties and subspecialties, into disciplines and subdisciplines according to body organs and systems, was often more pragmatic and historical than scientific. As scientific progress has advanced, for example, "genetics" as a discipline has become a "way of knowing" as well as a "tool" for all health care professionals. ${ }^{20}$ Similar transformations are observed for cellular, molecular and developmental biology, physiology, biochemistry, immunology, inflammatory diseases and disorders, autoimmune diseases and disorders, acute and chronic pain management, biostatistics, the Health Insurance Portability and Accountability Act (HIPAA) compliance, and so much more. These and many other important aspects of being a health professional are clearly "transdisciplinary" and argue for increased integration and collaboration between all health professionals. Bioinformatics is another such example: how to access information, be equipped to "mine" databases and extract relevant information for solving a specific question or problem.

We now know, for example, that the immune system and inflammation are closely related to many chronic diseases and disorders ${ }^{22}$ including hypertension, diabetes mellitus, arthritis, psoriasis, atherosclerotic cardiovascular disease, and periodontitis. The research-derived evidence (see recent consensus report) ${ }^{23}$ supports the assertion that physicians, dentists, nurses, pharmacists, and allied health professionals should be required to have a common knowledge base to enable seamless comprehensive care for patients and their families. Health promotion, risk assessment, disease prevention, diagnosis, treatment and therapeutics, and prognosis and outcomes, must be coordinated between all 
health professionals. ${ }^{24-26}$ This is particularly evident when considering the association between periodontal disease and cardiovascular disease. ${ }^{22,23}$ Similar calls for integration, cooperation, and collaboration between health professionals has been heralded for cohorts of patients and their families such as: congenital birth defects, for example syndromic and nonsyndromic cleft lip and palate (eg, pediatrics, surgery, anesthesiology, neurology, speech therapy, nursing, physical therapy, social services, embryology, pediatric dentistry and prosthodontics, etc); or head and neck cancers (eg, family medicine, internal medicine, oncology, radiology, dermatology, plastic surgery, oral and maxillofacial surgery, otolaryngology, etc). ${ }^{22}$

\section{Lessons learned}

Throughout my leadership experiences over four decades (1968-2010), I have observed and learned that humans possess a passion to understand and predict the future, and that a transformational leader takes on the responsibility for molding and shaping the possibilities within a tangible dream of the future. I have also learned that success is never $100 \%$. From my perspective, highly successful leaders possess unconditional integrity, charisma, and a powerful drive for authenticity. Based on my experiences within academics, federal agencies, and private industry, I enthusiastically endorse the key principles of leadership for the 21 st Century, here adopted from Bennis and Thomas' "Geeks and geezers: how era, values, and defining moments shape leaders" (2002). ${ }^{3}$

- Greatness starts with superb people; recruitment of talent is essential.

- Great groups and great leaders create each other.

- Every great group has a strong and effective leader.

- The leaders of great groups love talent and know where to find it.

- Great groups are full of talented people who can work together.

- Great groups think they are "on a mission from God".

- Every great group is an island - but an island with a bridge to the mainland.

- Great groups see themselves as "winning underdogs".

- Great groups always have an external threat or "enemy".

- People in great groups are enormously focused and "have blinders on".

- Great groups are optimistic, not realistic, and sense that "anything is possible".

- In truly great groups the right person has the right job.

- The leaders of great groups give them what they need, remove obstacles, and always promote creativity.

- Great groups produce dreams with deadlines (they are action groups).

- Great work is its own reward (incentives help).

I invite the reader to reflect on outstanding leadership coupled with great groups or teams that they have personally experienced, and then compare your experiences and assessments with those characteristics highlighted by Professor Warren Bennis. Sharing the lessons learned from highly innovative leadership moments can illustrate principles and select techniques of leadership. ${ }^{27,28}$ Nine leadership moments led to nine leadership principles as learned and then described by Michael Useem, as follows: ${ }^{27}$

Roy Vagelos at Merck

Wagner Dodge in Mann Gulch

Eugene Kranz and Apollo ${ }^{13}$ Arlene Blum on Annapurna

Joshua Lawrence Chamberlain

Clifton Wharton at TIAA-CREF

John Gutfreund at Salomon Nancy Barry at Women's Banking

Alfredo Cristiani in El Salvador
Know yourself: understanding your values and where you want to go will assure that you know which paths to take.

Explain yourself: only then can your associates understand where you want to go and whether they want to accompany you.

Expect much: demanding the best is a prerequisite for obtaining it.

Gain commitment: obtaining consensus before decision will mobilize those you are counting upon after the decision.

Build now: acquiring support today is indispensable if you plan to draw upon it tomorrow.

Prepare yourself: seeking varied and challenging assignments now develops the confidence and skills required for later.

Move fast: inaction can often prove as disastrous as inept action. Find yourself: liberating your leadership potential requires matching your goals and talents to the right organization.

Remain steadfast: faith in your vision will ensure that you and your followers remain unswerving in pursuit of it.

As an exercise, the reader is encouraged to reflect on the triumphs and the disasters as part of their leadership 
experiences. Use these as "case studies" that can become "lessons learned" and extremely useful for leadership training and development. Further, revisit this exercise at different stages of your life and within diverse social, economic and political contexts. The nine examples shown above, in my opinion, are very beneficial towards leadership training and development. ${ }^{27}$ In particular, leaders with a command of history coupled with great storytelling have often become transformational leaders as documented in Howard Gardner's "Leading minds". ${ }^{28}$ Gardner discovered that informal as well as formal speeches by great leaders, such as George C Marshall, Winston Churchill, Franklin D Roosevelt, Margaret Mead, and Mahatma Gandhi, were almost always highly persuasive, mobilizing, and rich in metaphor and historical truths. ${ }^{28}$

I have been inspired by President Steve Sample and Professor Warren Bennis that broad reading habits (ie, "the great books", biography and history, great fiction) actually translate into "seeds" that motivate leaders to better understand the human condition throughout the ages. I find that leaders, especially transformational leaders, love to read, learn, and revise their understanding and views of the world.

\section{Summary and prospectus}

I assert that the future of leadership in the health care workforce, whether within public or private organizations, will continue to require creative, interdisciplinary, and most often culturally diverse collaborations. The structure and mission of existing traditional agencies and organizations are, and will continue to be, rapidly changing. Command and control, anchored to ownership or formal authority, is being replaced by an intermixture of tentative and changing teams of people organized to solve problems within predefined timelines and budgets. Solving problems that are significant to the larger society will increasingly dominate the public and private sectors - health and well-being, health care, energy, deficits, credit and savings, science and technology literacy, retirement versus work, terrorism, etc.

Academic medicine, dentistry, pharmacy, nursing, and allied health professions will be required to meet the rapidly changing needs of the larger culturally diverse society through major revisions of their academic programs, as well as the design and implementation of integrated education, research, and clinical research and clinical services. The amount of change in organizations has grown tremendously over the past few decades, and the rate of change will rapidly accelerate into the future. Leading change will increasingly be required. National debates over entitlements versus commodity when discussing health care will continue. Predicted as well as unanticipated changes must be part of business plans as well as national policies, as we have learned during the last decade. Numerous social, economic, and political factors will continue to shape many directions for change. Communities that present excessive burdens of disease based upon socioeconomic determinants will increasing require a culturally competent health care workforce that will emphasize health literacy, health promotion, disease prevention, and risk assessment that can effectively reduce health disparities in America. Our future will present a culturally diverse health care workforce (eg, clinicians, scientists, engineers, sociologists, law and public policy, business, and journalism) that must be educated and trained to meet our nation's needs for wellness in the 21 st Century.

"It is not just how many followers one has; it is also how many leaders one has created among them. The more leadership in the ranks, the more effective is one's own". ${ }^{27}$

\section{Michael Useem \\ Director of the Wharton School's Center for Leadership and Change}

\section{Acknowledgments}

The author's prism has been influenced over these many years being a tenured faculty within a research-intensive private university, a previous director of one of the National Institutes of Health (NIH) institutes (ie, the National Institute of Dentistry and Craniofacial Research (NIDCR)), a previous chairman of academic departments (eg, biochemistry and nutrition, craniofacial biology), a previous dean of a school of dentistry, a member of the IOM, and a director within a board of directors for a major corporation listed on the stock exchange. I also wish to acknowledge my inspirations including John Ingle, Lucien Bavetta, Richard Greulich, George Martin, Dushanka Kleinman, Warren Bennis, Steve Sample, Harold Varmus, Lloyd Armstrong, and Max Nikias, from whom so much has been learned about the commitment to responsible change and service to a better future.

\section{Disclosure}

The author reports no conflicts of interest in the material presented.

\section{References}

1. Bennis WG. Managing the Dream: Reflections on leadership and change. Cambridge, MA: Perseus; 2000.

2. Bennis W, Spreintzer GM, Cummings TC, editors. The Future of Leadership. San Francisco, CA: Jossey-Bass; 2001. 
3. Bennis WG, Thomas RJ. Geeks and Geezers: How era, values, and defining moments shape leaders. Boston, MA: Harvard Business School Press; 2002.

4. Sample SB. The Contrarian's Guide to Leadership. San Francisco, CA: Jossey-Bass; 2002.

5. Santafegroup.org. The Santa Fe Group. Available from http://www. santafegroup.org/Accessed January 10, 2010.

6. Hesselbein F, Goldsmith M, Beckhard P. The Organization of the Future. San Francisc, CA: Jossey-Bass; 1997.

7. Goldsmith M, Underhill BO. Multisource feedback for executive development. In Institute of Medicine. Bracken DW, Timmreck CW, Church AH (editors). The Handbook of Multisource Feedback. San Francisco, CA: Jossey-Bass; 2001:225-288.

8. Reports of the Institute of Medicine. Available from: http://www.iom. org/reports/Accessed January 10, 2010.

9. Crowley WF Jr, Sherwood L, Salber P, et al. Clinical research in the United States at a crossroads: proposal for a novel public - private partnership to establish a national clinical research enterprise. JAMA 2004;291(9):1120-1126.

10. Kupersmith J, Sung N, Myron G, et al. Creating a new structure for research on health care effectiveness. J Invest Med. 2005;53(2): 67-72.

11. Kohn LT, editor. Academic Health Centers: Leading change in the 21st century. Washington, DC: The National Academy Press; 2003.

12. Koh GC, Khoo HE, Wong ML. The effects of problem-based learning during medical school on physician competency: a systematic review. CMAJ. 2008;1781(1):34-41

13. Fincham AG, Shuler CF. The changing face of dental education: the impact of PBL. J Dent Ed. 2001;65(5):406-421.

14. Dalrymple KR, Wuenschell C, Shuler CF. Development and implementation of a comprehensive faculty development program in $\mathrm{PBL}$ core skills. J Dental Ed. 2006;70(9):948-955.

15. Dalrymple KR, Wong S, Rosenblum A, et al. Core skills faculty development. Workshop 3: understanding PBL process assessment and feedback via scenario-based discussions, observation, and role-play. $J$ Dent Ed. 2007;71(12):1561-1573.
16. Neville AJ. Problem-based learning and medical education forty years on: a review of its effects on knowledge and clinical performance. Med Princ Pract. 2009;18(1):1-9.

17. Mouradian WE, Reeves A, Kim S, et al. An oral health curriculum for medical students at the University of Washington. Acad Med. 2005;80(5):434-442.

18. Slavkin HC, Lawrence L. Incorporating leadership knowledge and skills into the dental education community. J Dent Ed. 2007;71(6):708-712.

19. Senge PM. The Fifth Discipline: The art and practice of the learning organization. New York, NY: Doubleday Publishers; 1990.

20. Collins FS. The Language of Life: DNA and the revolution in personalized medicine. New York, NY: HarperCollins Publishers; 2010.

21. Slavkin HC. Leadership in research: organizing genius. JAm Coll Dent. 2005;71(4):33-38.

22. Slavkin HC, Baum BJ. Relationship of dental and oral pathology to systemic illness. JAMA. 2000;284:1215-1217.

23. Friedewald VE, Kornman KS, Beck JD, et al. The American Journal of Cardiology and Journal of Periodontology editors' consensus: periodontitis and atherosclerotic cardiovascular disease. J Periodontol. 2009;80(7):1021-1032.

24. Sung N, Crowley W, Genel M, et al. Central challenges facing the national clinical research enterprise. JAMA. 2003;289:1278-1287.

25. DePaola D, Slavkin HC. Reforming dental health professions education: a white paper. J Dent Ed. 2004;68(11):1139-1150.

26. Slavkin HC. The failure of dentistry's social contract with America and California's search for legislative solutions. J Dent Ed. 2003; 67(10):1076-1087.

27. Useem M. The Leadership Moment. New York, NY: Random House Publishers; 1998.

28. Gardner H. Leading Minds: An anatomy of leadership. New York, NY: Basic Books; 1995.
Journal of Healthcare Leadership

\section{Publish your work in this journal}

The Journal of Healthcare Leadership is an international, peer-reviewed, open access journal focusing on leadership for the health profession. The journal is committed to the rapid publication of research focusing on but not limited to: Healthcare policy and law; Theoretical and practical aspects healthcare delivery; Interactions between healthcare and society and evidence-based practices;

\section{Dovepress}

Interdisciplinary decision-making; Philosophical and ethical issues; Hazard management; Research and opinion for health leadership; Leadership assessment. The manuscript management system is completely online and includes a very quick and fair peer-review system. Visit http://www.dovepress.com/ testimonials.php to read real quotes from published authors. 